\title{
Impact of Medicaid expansion on smoking prevalence and quit attempts among those newly eligible, 2011-2019
}

\author{
Katy Ellis Hilts', Justin Blackburn', P. Joseph Gibson'², Valerie A. Yeager', Paul K. Halverson', Nir Menachemi'
}

\begin{abstract}
INTRODUCTION Low-income populations have higher rates of smoking and are disproportionately affected by smoking-related illnesses. This study assessed the long-term impact of increased coverage for tobacco cessation through Medicaid expansion on past-year quit attempts and prevalence of cigarette smoking.

METHODS Using data from CDC's annual Behavioral Risk Factor Surveillance System 2011-2019, we conducted difference-in-difference regression analyses to compare changes in smoking prevalence and past-year quit attempts in expansion states versus non-expansion states. Our sample included non-pregnant adults (18-64 years old) without dependent children with incomes at or below $100 \%$ of the Federal Poverty Level (FPL).

RESULTS Regression analyses indicate that Medicaid expansion was associated with reduced smoking prevalence in the first two years post-expansion $(\beta=-0.019$, $\mathrm{p}=0.04$ ), but that this effect was not maintained at longer follow-up periods $(\beta=-0.006, p=0.49)$. Results of regression analyses also suggest that Medicaid expansion does not significantly impact quit attempts in the short-term $(\beta=-0.013$, $\mathrm{p}=0.52)$ or at longer term follow-up $(\beta=-0.026, p=0.08)$.

CONCLUSIONS Expanded coverage for tobacco cessation services through Medicaid alone may not be enough to increase quit-attempts or sustain a reduction in overall prevalence of smoking in newly eligible populations over time. Medicaid programs should consider additional strategies, such as public education campaigns and removal of barriers, to support cessation among enrollees.
\end{abstract}

\section{AFFILIATION}

1 Richard M. Fairbanks School of Public Health, Indiana University, Indianapolis, United States 2 Marion County Public Health Department, Indianapolis, United States

\section{CORRESPONDENCE TO}

Katy Ellis Hilts. Richard M. Fairbanks School of Public Health, Indiana University, 1050 Wishard Blvd., Indianapolis, IN 462022872600, United States. E-mail: kaaellis@iupui.edu ORCID ID: https://orcid.org/00000002-6676-2767

\section{KEYWORDS}

Medicaid, health policy, tobacco use cessation

Received: 26 May 2021

Revised: 24 June 2021

Accepted: 3 July 2021

\section{INTRODUCTION}

Tobacco use remains the leading cause of preventable death and disease in the US resulting in more than 0.48 million deaths annually ${ }^{1}$. Low-income and Medicaid-eligible populations have higher rates of smoking than the general population and are disproportionately affected by smoking-related illnesses ${ }^{2}$. Medicaid expansion, following the passage of the Patient Protection and Affordable Care Act (ACA), increased access to coverage for tobacco cessation counseling and medications to millions of uninsured adults in the US including an estimated 2.3 million adult smokers ${ }^{3,4}$. Expanded coverage for tobacco cessation treatments has the potential to reduce the prevalence of smoking ${ }^{5}$, increase the likelihood of a person attempting to quit ${ }^{6,7}$, improve health outcomes ${ }^{8}$, and reduce tobacco related healthcare spending 9 .

Previous research on tobacco cessation in the context of the ACA has focused on how tobacco related provisions of the law are covered by various health plans across the country ${ }^{10}$; the potential impact of ACA allowable tobacco surcharges ${ }^{11}$; and whether or not expanded access to health insurance resulted in an increase in unhealthy behaviors, such as smoking ${ }^{12,13}$. Additionally, studies have examined state-specific impacts of Medicaid expansion on smoking cessation ${ }^{14}$ or how changes 
in Medicaid policies have affected the uptake of cessation medications ${ }^{15}$. Results varied across early studies assessing the impact of increased coverage for tobacco cessation through Medicaid following the passage of the ACA, with one study reporting that expansion was associated with increases in smoking cessation attempts ${ }^{16}$, another reporting that it was associated with decreases in overall prevalence $^{17}$, and a third indicating that Medicaid expansion was not associated with increases in quit attempts or cessation ${ }^{18}$. Importantly, these early studies only included data within the first two years post Medicaid expansion. Additional rigorous studies with longer time horizons are needed to more comprehensively understand how Medicaid expansion's facilitation of smoking cessation treatments affected smoking behaviors particularly for newly eligible populations.

The current study builds on previous research by providing additional precision and evidence about the impact of the ACA Medicaid expansion on tobacco cessation quit attempts and smoking prevalence over time. We use 9 years of data, including 6 years post expansion, to conduct difference-in-difference analyses that measure changes in smoking prevalence and past year quit attempts in expansion and non-expansion states. The results of this study will be valuable in assisting state and federal policymakers, payers, and others interested in tobacco related outcomes in understanding the long-term impact these policies may have on addressing tobacco use among newly eligible Medicaid populations.

\section{METHODS}

\section{Study sample}

We use data from the Center for Disease Control and Prevention's (CDC) Behavioral Risk Factor Surveillance System (BRFSS) covering 2011-2019. We measure differences in the change in likelihood of reporting a quit attempt in the past year (henceforth 'quit attempts') and current smoking prevalence between states that expanded Medicaid coverage for tobacco cessation and states that did not. The BRFSS is an annual telephone survey conducted in the US to gather information on health behaviors and health outcomes. The weighted survey data provides a representative sample for each state and the District of
Columbia, with approximately 0.5 million responses annually ${ }^{19}$. The large sample size, timeliness of data, and inclusion of state identifiers in BRFSS data allows for a comprehensive assessment of the potential effect of Medicaid expansion on tobacco cessation across states over time.

The study period includes 3 years of data from pre-expansion (2011-2013) and 6 years of data from post-expansion (2014-2019). We use data from questions included in the core component of the survey, which are consistent for all states. Our sample population includes adults who traditionally would not have been covered by Medicaid prior to expansion. More specifically, the sample consists of non-pregnant childless adults aged 18-64 years with household incomes at or below the $100 \%$ Federal Poverty Level (FPL). While individuals with household incomes between $100 \%$ and $138 \%$ of the FPL were also newly eligible for coverage as a result of Medicaid expansion, they also became newly eligible for subsidies giving them potential access to coverage for tobacco cessation through the ACA marketplace plans in all states starting in 2014, and therefore were not included in our sample ${ }^{12,20}$. We had a final weighted sample of 130944640 individuals with $34.5 \%$ residing in non-expansion states and $65.5 \%$ residing in a non-expansion state at the time of their interview.

\section{Measures}

Medicaid expansion, measured at the state level, is the main independent variable for this study. States that had expanded Medicaid following passage of the ACA by 31 December 2019, were considered to be an expansion state. While some states did partially expand Medicaid and related benefits to lowincome adults prior to 2014 , these states almost all experienced considerable expansion in or after 2014 and thus were included in our main analyses ${ }^{12,21}$. Further, as not all states expanded at the same time, individuals were not considered to be in the postexpansion group unless their interview data occurred after the quarter in which their state implemented its expansion. The Supplementary file provides a complete list of expansion and non-expansion states. Our two main dependent variables are self-reported past year quit attempt and overall smoking prevalence. Five questions in the core component of the BRFSS 
survey specifically address tobacco use and quit attempts.

We used the smoking status questions in BRFSS to measure current smoking. A current smoker was defined as someone who reported both having smoked at least 100 cigarettes in their lifetime and reported currently smoking on some days or every day. A former smoker was defined as someone who reported smoking at least 100 cigarettes in their lifetime but did not report currently smoking at the time of the survey. Our analyses for quit attempts only included data for individuals that reported being a current or former smoker and had reported attempting to quit in the twelve months prior to their interview. Specifically, current smokers were considered to have made a quit attempt if they answered yes to the question: 'During the past 12 months, have you stopped smoking for one day or longer because you were trying to quit smoking?'. Former smokers were considered to have made a quit attempt if they indicated that they had smoked within the past year, in answering the question: 'How long has it been since you last smoked a cigarette, even one or two puffs?'.

In addition to the main outcome variables, we also included state level tobacco related policies, cigarette excise taxes and smoke-free air laws, as control variables for our regression models. These policies have been shown to increase quit attempts and decrease overall tobacco use, which could influence our dependent variables ${ }^{1}$. We also controlled for respondent demographic characteristics including age, gender, race/ethnicity, education level, and marital status in our models.

\section{Statistical analyses}

We computed difference-in-difference regression models to compare the changes in the dependent variables in expansion states to changes in the same variables in non-expansion states. Identification of a potential treatment effect using differencein-difference estimation relies on the assumption that expansion and non-expansion states exhibited parallel trends for the outcomes of interest. To test this assumption, we first visually assessed graphs of the trends and then assessed them statistically. Specifically, we estimated regressions interacting the expansion group indicator with year indicator variables for all years except our reference year, 2013, which was the last year prior to expansion. We then used a joint-F test to assess whether all pre-expansion years were jointly non-significant to further test this assumption.

For our difference-in-difference regression analyses we use the following model to provide estimates for each outcome variable:

$$
\begin{aligned}
& Y_{i s t}=a+\beta(\text { Treatment })+\beta\left(\text { Post }_{t}\right) \\
& +\beta\left(\text { Treatment }_{s} \times \text { Post }_{t}\right)+\gamma X_{s t}+\eta Z_{\text {ist }}+\varepsilon
\end{aligned}
$$

$Y_{i s t}$ represents binary outcome variables (current smoking and past year quit attempt) for an individual $i$, living in a specific state $s$, at a specific time $t$. We estimated linear probability models for binary outcomes. We also ran logit models and results did not change, and therefore present the results of our linear probability models as they provide reliable estimates of average effects and allow for ease of interpretation $^{22}$. The treatment variable is a binary variable with 1 representing individuals living in an expansion state and 0 representing individuals living in non-expansion states. The post variable is a binary variable equaling 1 if an interview date occurred on or after 1 January 2014 or 0 if the interview date occurred before 1 January 2014. For states that expanded after 1 January 2014, the post variable was 0 until the expansion took effect in that state after which it became a 1 (Supplementary file). $X$ represents the state policy control variables and $Z$ represents demographic control variables; $\varepsilon$ represents the error term, clustered by state, and includes all other unobservable factors that might bias the relationship between the intervention and the outcome variables.

In addition to our main regression models, we also conducted sub-analyses to assess if there were any differing effects due to timing or variations in expansions across states. First, to compare our results to earlier studies, we ran analyses using data through the first two years post expansion (2011-2015). Additionally, separate models considered states that expanded coverage prior to or on 1 January 2014 (main expansion) versus non-expansion states and states that expanded coverage after 1 January 2014 (delayed expansion) versus non-expansion states. Lastly, as it likely took time for changes in 
enrollment and utilization of services to occur, we also ran our models using a 1-year lag for expansion. All analyses included BRFSS sampling weights and were conducted using SAS version 9.4.

\section{RESULTS}

Based on our visual assessment, expansion and non- expansion states had similar trends for smoking prevalence and quit attempts (Figures 1 and 2). Results of our formal tests confirmed the findings of our graphical assessments that there was no difference in trends for our outcome variables during the preexpansion period.

Descriptive results of our sample are given in

Figure 1. Trends in smoking prevalence by expansion status

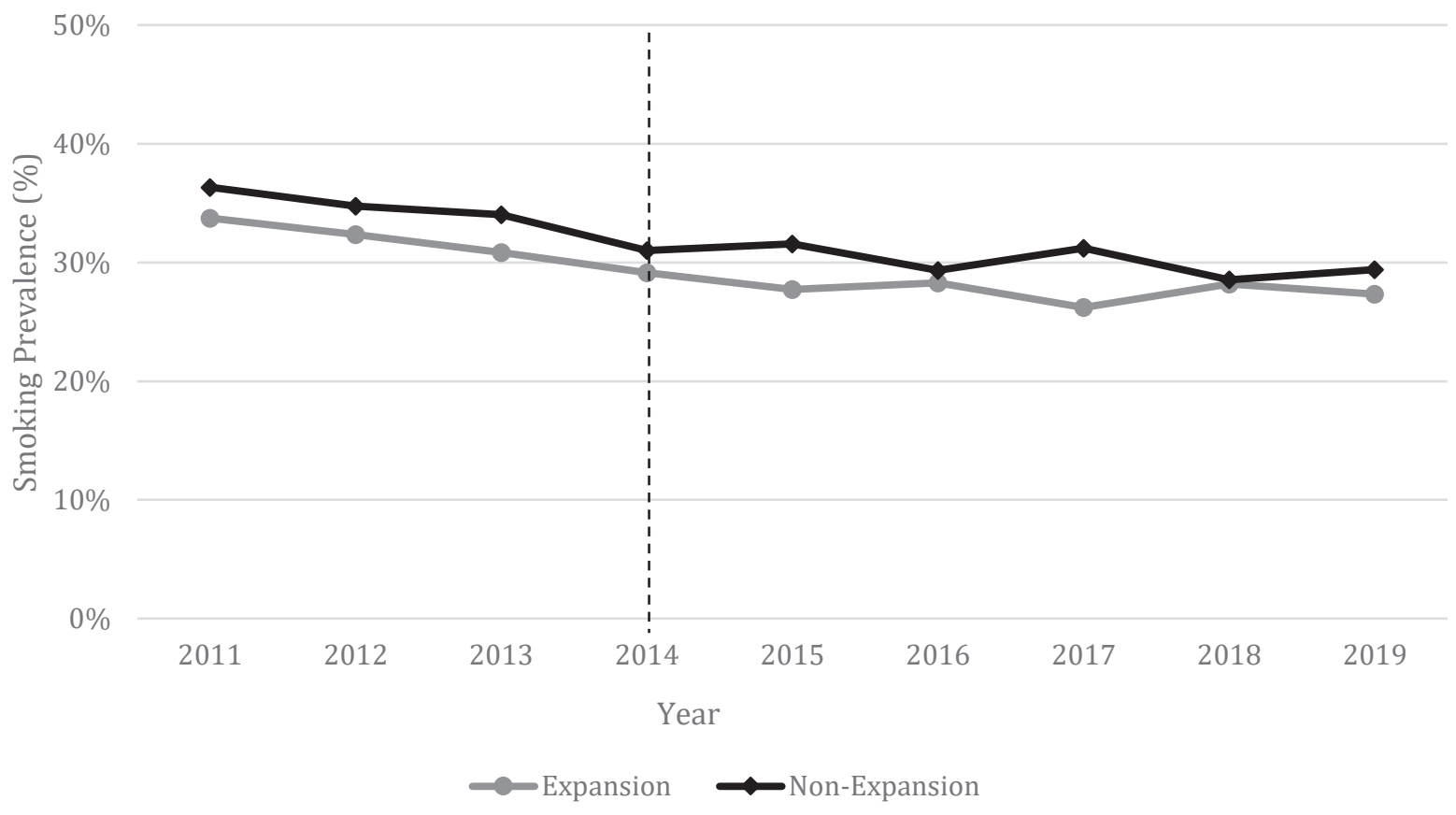

Figure 2. Trends in percent of past-year quit attempts by expansion status

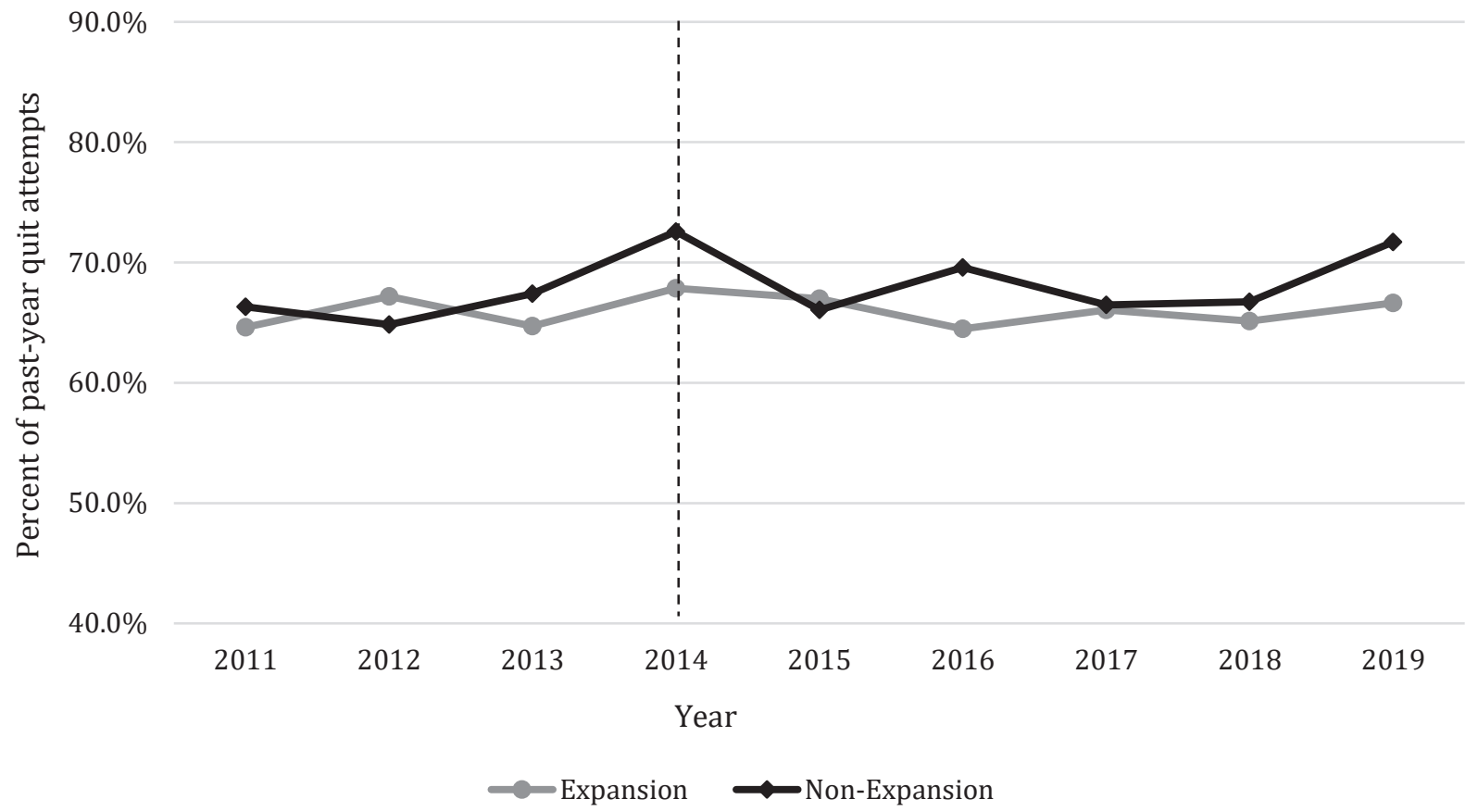


Table 1, overall and stratified by Medicaid expansion. Individuals in our sample that lived in a state that had expanded Medicaid coverage were more likely to be younger (18-34 years) than older (35-64 years) (38.9\% vs $34.2 \%)$, Hispanic than non-Hispanic $(24.3 \%$ vs $22.2 \%, \mathrm{p}<0.001)$, and have more than a high school degree (39.6\% vs $36.7 \%)$. Those living in states without expanded Medicaid coverage were more likely to be Black, non-Hispanic (22.9\% vs $14.4 \%$ ) and report being married or unmarried couple $(30.4 \%$ vs $27.6 \%)$ compared to individuals living in a state with expanded Medicaid coverage $($ all $\mathrm{p}<0.001)$. The average smoking rate in states that had expanded coverage was $29.2 \%$ compared to $31.6 \%$ in states that had not expanded $(\mathrm{p}<0.001)$, and the percent of past year quit attempts in states with expanded coverage was $66.0 \%$ versus $68.1 \%$ in states that had not expanded $(\mathrm{p}<0.001)$.

Results of our main difference-in-difference model and sub-analyses estimating the impact of Medicaid expansion for smoking prevalence are shown in Table 2 . In our main model, we found that

Table 1. Weighted descriptive statistics stratified by state Medicaid coverage

\begin{tabular}{|c|c|c|c|c|}
\hline Characteristic & Overall & $\begin{array}{l}\text { State without } \\
\text { expanded } \\
\text { Medicaid } \\
\text { coverage } \\
n\end{array}$ & $\begin{array}{c}\text { State with } \\
\text { expanded } \\
\text { Medicaid } \\
\text { coverage } \\
n\end{array}$ & $p$ \\
\hline Count & 180894 & 63684 & 117210 & \\
\hline \multirow[t]{2}{*}{ Weighted count } & 130944640 & 45138277 & 85806363 & \\
\hline & $\%$ & $\%$ & $\%$ & \\
\hline \multicolumn{5}{|l|}{ Gender } \\
\hline Female & 47.6 & 48.1 & 47.3 & 0.04 \\
\hline \multicolumn{5}{|l|}{ Age (years) } \\
\hline $18-24$ & 22.6 & 21.2 & 23.4 & $<0.001$ \\
\hline $25-34$ & 14.6 & 13.0 & 15.5 & \\
\hline $35-44$ & 11.9 & 12.2 & 11.7 & \\
\hline $45-54$ & 23.2 & 24.6 & 22.5 & \\
\hline $55-64$ & 27.6 & 29.0 & 26.9 & \\
\hline \multicolumn{5}{|l|}{ Race/ethnicity } \\
\hline White, non-Hispanic & 47.9 & 47.3 & 48.3 & $<0.001$ \\
\hline Black, non-Hispanic & 17.3 & 22.9 & 14.4 & \\
\hline Other, non-Hispanic & 7.7 & 4.3 & 9.5 & \\
\hline Multiracial, non-Hispanic & 1.9 & 1.7 & 2.0 & \\
\hline Hispanic & 23.6 & 22.2 & 24.3 & \\
\hline Unknown & 1.5 & 1.5 & 1.5 & \\
\hline \multicolumn{5}{|l|}{ Education level } \\
\hline Less than high school & 27.4 & 29.0 & 26.6 & $<0.001$ \\
\hline High school graduate & 34.0 & 34.3 & 33.8 & \\
\hline More than high school & 38.6 & 36.7 & 39.6 & \\
\hline \multicolumn{5}{|l|}{ Marital status } \\
\hline Not married or part of an unmarried couple & 71.4 & 69.6 & 72.4 & $<0.001$ \\
\hline Married or part of unmarried couple & 28.6 & 30.4 & 27.6 & \\
\hline Smoking prevalence & 30.1 & 31.6 & 29.2 & $<0.001$ \\
\hline Past year quit attempt* & 66.7 & 68.1 & 66.0 & 0.005 \\
\hline Smoke-free air law & 43.5 & 5.6 & 63.4 & $<0.001$ \\
\hline Excise tax & $\$ 1.62$ & $\$ 0.93$ & $\$ 1.99$ & $<0.001$ \\
\hline
\end{tabular}

${ }^{*}$ Only measured among current smokers and former smokers that had quit within the last year $(n=68305$; weighted count $=44758012)$ 
Table 2. Difference-in-difference estimates of the impact of Medicaid expansion on current smoking, 20112019

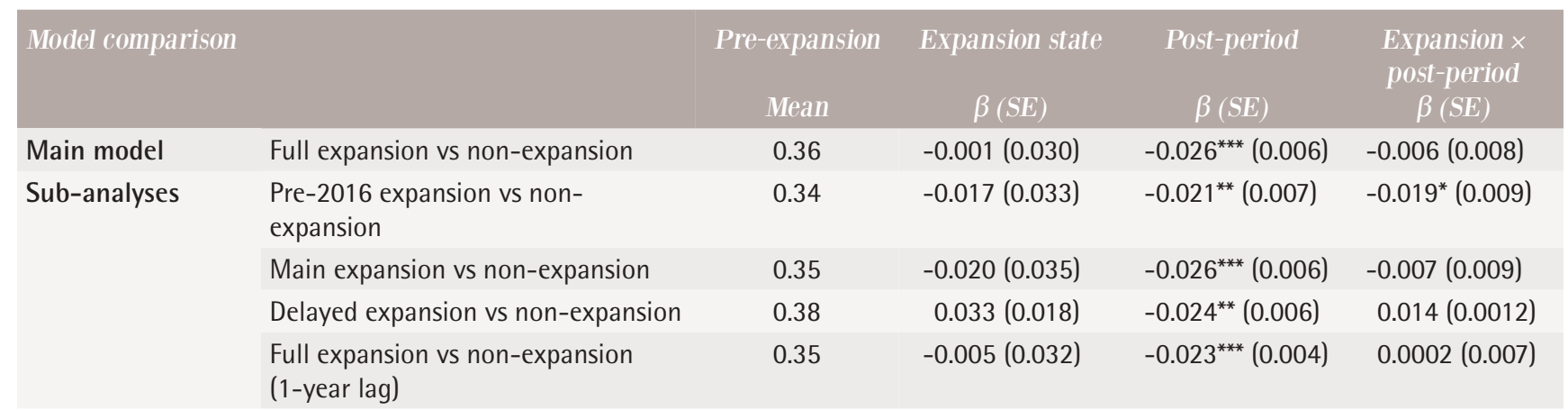

Each model controls for age, gender, race/ethnicity, education level, marital status, and state level policy controls (smoke-free air and excise tax).

Table 3. Difference-in-difference estimates of the impact of Medicaid expansion on past-year quit attempts, 2011-2019

\begin{tabular}{|c|c|c|c|c|c|}
\hline \multicolumn{2}{|l|}{ Model comparison } & \multirow{2}{*}{$\begin{array}{c}\text { Pre-expansion } \\
\text { Mean }\end{array}$} & \multirow{2}{*}{$\begin{array}{c}\text { Expansion state } \\
\qquad \beta(\mathrm{SE})\end{array}$} & \multirow{2}{*}{$\begin{array}{l}\text { Post-period } \\
\qquad \beta(\mathrm{SE})\end{array}$} & \multirow{2}{*}{$\begin{array}{c}\text { Expansion } \times \\
\text { post-period } \\
\beta(\mathrm{SE})\end{array}$} \\
\hline & & & & & \\
\hline Main model & Full expansion vs non-expansion & 0.68 & $-0.026(0.014)$ & $0.022^{*}(0.011)$ & $-0.026(0.015)$ \\
\hline \multirow[t]{4}{*}{ Sub-analyses } & $\begin{array}{l}\text { Pre- } 2016 \text { expansion vs non- } \\
\text { expansion }\end{array}$ & 0.67 & $-0.036^{*}(0.014)$ & $0.025(0.016)$ & $-0.013(0.020)$ \\
\hline & Main expansion vs non-expansion & 0.67 & $-0.040^{*}(0.016)$ & $0.021^{*}(0.010)$ & $-0.018(0.016)$ \\
\hline & Delayed expansion vs non-expansion & 0.70 & $0.005(0.008)$ & $0.022^{*}(0.05)$ & $-0.041^{* *}(0.013)$ \\
\hline & $\begin{array}{l}\text { Full expansion vs non-expansion } \\
\text { (1-year lag) }\end{array}$ & 0.69 & $-0.042^{* *}(0.011)$ & $-0.0002(0.005)$ & $-0.015(0.010)$ \\
\hline
\end{tabular}

Each model controls for age, gender, race/ethnicity, education level, marital status, and state level policy controls (smoke-free air and excise tax).

expanded coverage for tobacco cessation through Medicaid was not associated with a reduction in smoking prevalence in the long-term. Similarly, we did not find an effect in our stratified models for early adopters versus non-expansion, late adopters versus non-expansion, or when including a 1-year lag. We did, however, find an effect in our model which only considered data from two years postexpansion (2011-2015). In this model we found that states that had expanded Medicaid experienced a greater decrease in current smoking rates than those states that did not expand $(\beta=-0.019, p=0.04)$.

Results of our main difference-in-difference model and sub-analyses estimating the impact of Medicaid expansion for past-year quit attempts are shown in Table 3 . Results of our main model suggest that the change in past-year quit attempts pre- and post-expansion were not significantly different in states that had expanded Medicaid coverage compared to those states without expanded coverage. This again remained valid for most of our stratified models except for late adopters versus non-expansion states. We found that late adopter states experienced smaller increases in past-year quit attempts compared to non-expansion states $(\beta=-$ $0.041, \mathrm{p}=0.005)$.

\section{DISCUSSION}

The current study used additional years of data to examine whether expanded coverage impacts smoking cessation or prevalence over a longer sustained time period. We found that Medicaid expansion impacted smoking prevalence in the first two years post expansion, but this effect did not persist in the longer follow-up period. Further, we did not find a significant impact of expanded coverage on quit attempts in either short-term or longer follow-up period. Early studies assessing the impact of increased coverage 
for tobacco cessation through Medicaid following the passage of the ACA reported mixed results, with one study reporting improvements in recent smoking cessation ${ }^{16}$, another reporting that increased coverage was associated with decreases in overall prevalence ${ }^{17}$, and a third indicating that expanded coverage was not associated with increases in quit attempts or cessation $^{18}$. While informative, these early studies are limited by focusing on data from within the first two years post expansion.

When examining early versus late Medicaid expanding states, as well as using lagged dependent variables, we produced similar results to our main models, providing added confidence in our findings. However, a secondary finding of our study is that late adopting Medicaid expansion states had smaller increases in quit attempts possibly due to differences in sociopolitical factors in late-adopter states versus early adopter states. Specifically, Medicaid expansion has been heavily influenced by partisan politics, leading to delays and variation in adoption and implementation across states ${ }^{23}$. While our models attempt to account for this state level variation, future research should consider how these additional factors may influence tobacco related outcomes.

Overall, results from our study suggest that while expanded coverage for tobacco cessation services through Medicaid may have short-term impacts which were most pronounced in early expansion states, these effects on smoking behaviors among low-income adults without dependent children are not present in the long-term or to the same degree in later expanding states. Importantly, these findings may indicate that increased coverage alone may not be enough to increase quit attempts and decrease overall smoking prevalence. In the context of Medicaid policies, even among states that expanded, many barriers remain that may limit full use of cessation services among expansion populations ${ }^{24}$. Specifically, almost half of all states require copayments for cessation services, two-thirds put annual limits on quit attempts, and approximately three-fourths of states require pre-authorization and enforce duration limits for services ${ }^{24}$. Further, previous research has suggested that provider and member education is associated with increased use of services and subsequent reductions in smoking rates $^{25,26}$. Thus, while Medicaid expansions following the passage of the ACA increased access to coverage for smoking cessation, the impact of expanded coverage may be significantly mediated by the presence or absence of supporting policies and education.

\section{Limitations}

It is important to note the limitations of our study. First, the use of BRFSS data, which rely on selfreported information, may underestimate the number of smokers because respondents may under-report smoking due to social stigma against smoking. However, previous research indicates that smoking rates from BRFSS data are appropriate to use when assessing smoking-related outcomes, such as prevalence and past year quit attempts, in the $\mathrm{US}^{27}$. Another limitation is that BRFSS data do not consistently include a question related to the type of coverage an individual has which limits our ability to accurately determine if an individual was enrolled in Medicaid. Instead, we rely on income and eligibility cutoffs to categorize individuals. Additionally, we were unable to determine if individuals who reported quitting utilized any of the newly covered cessation services or medications from BRFSS data. While using BRFSS data has its limitations, this dataset is among the most comprehensive available and has been used in previous studies to assess the impact of Medicaid expansion ${ }^{12,16}$. Also, by limiting our sample to $100 \%$ of the federal poverty level we were unable to determine what proportion of the estimated 2.3 million newly covered adult smokers were accounted for in our study $^{4}$. Lastly, as the current study was focused on how increased access to coverage impacted cessationrelated outcomes, we did not assess how barriers to services impacted smoking prevalence or quit attempts. Future studies should attempt to understand the impact of barriers, such as prior authorization or coverage limitations, on cessation-related outcomes.

\section{CONCLUSIONS}

Tobacco use remains a leading cause of preventable death and disease, especially among low-income populations, in the US. The results of this study suggest that expanded coverage for tobacco cessation services through Medicaid alone may not change the likelihood of attempting to quit or reduce overall prevalence of smoking beyond the first short period 
following expansion in select early adopting states. Medicaid programs should consider additional strategies that can further increase the likelihood of members attempting to quit. Future research should explore how different strategies, such as public education campaigns and removal of barriers (e.g. prior authorization, coverage limitations) influence the use of cessation services and impact smoking rates among low-income populations.

\section{REFERENCES}

1. U.S. Department of Health and Human Services. Smoking Cessation: A Report of the Surgeon General. U.S. Department of Health and Human Services, Centers for Disease Control and Prevention, National Center for Chronic Disease Prevention and Health Promotion, Office on Smoking and Health; 2020. Accessed June 24, 2021. https://www.hhs.gov/sites/default/files/2020-cessationsgr-full-report.pdf

2. Jamal A, Phillips E, Gentzke AS, et al. Current Cigarette Smoking Among Adults - United States, 2016. MMWR Morb Mortal Wkly Rep. 2018;67(2):53-59. doi:10.15585/mmwr.mm6702a1

3. Chang T, Davis M. Potential Adult Medicaid Beneficiaries Under the Patient Protection and Affordable Care Act Compared With Current Adult Medicaid Beneficiaries. Ann Fam Med. 2013;11(5):406-411. doi:10.1370/afm.1553

4. DiGiulio A, Haddix M, Jump Z, et al. State Medicaid Expansion Tobacco Cessation Coverage and Number of Adult Smokers Enrolled in Expansion Coverage United States, 2016. MMWR Morb Mortal Wkly Rep. 2016;65(48):1364-1369. Accessed June 24, 2021. https://www.cdc.gov/mmwr/volumes/65/wr/pdfs/ mm6548a2.pdf

5. Land T, Warner D, Paskowsky M, et al. Medicaid Coverage for Tobacco Dependence Treatments in Massachusetts and Associated Decreases in Smoking Prevalence. PLoS One. 2010;5(3):e9770. doi:10.1371/journal.pone.0009770

6. Greene J, Sacks RM, McMenamin SB. The Impact of Tobacco Dependence Treatment Coverage and Copayments in Medicaid. Am J Prev Med. 2014;46(4):331336. doi:10.1016/j.amepre.2013.11.019

7. Kostova D, Xu X, Babb S, McMenamin SB, King BA. Does State Medicaid Coverage of Smoking Cessation Treatments Affect Quitting? Health Serv Res. 2018;53(6):4725-4746. doi:10.1111/1475-6773.12979

8. Land T, Rigotti NA, Levy DE, et al. A Longitudinal Study of Medicaid Coverage for Tobacco Dependence Treatments in Massachusetts and Associated Decreases in Hospitalizations for Cardiovascular Disease. PLoS Med. 2010;7(12):e1000375. doi:10.1371/journal.pmed.1000375

9. Richard P, West K, Ku L. The Return on Investment of a Medicaid Tobacco Cessation Program in Massachusetts. PLoS
One. 2012;7(1):e29665. doi:10.1371/journal.pone.0029665

10. McMenamin SB, Yoeun SW, Halpin HA. Affordable Care Act Impact on Medicaid Coverage of Smoking-Cessation Treatments. Am J Prev Med. 2018;54(4):479-485. doi:10.1016/j.amepre.2018.01.016

11. Friedman AS, Schpero WL, Busch SH. Evidence Suggests That The ACA's Tobacco Surcharges Reduced Insurance Take-Up And Did Not Increase Smoking Cessation. Health Aff (Millwood). 2016;35(7):1176-1183. doi:10.1377/hlthaff.2015.1540

12. Simon K, Soni A, Cawley J. The Impact of Health Insurance on Preventive Care and Health Behaviors: Evidence from the First Two Years of the ACA Medicaid Expansions. J Policy Anal Manage. 2017;36(2):390-417. doi:10.1002/pam.21972

13. Cawley J, Soni A, Simon K. Third Year of Survey Data Shows Continuing Benefits of Medicaid Expansions for Low-Income Childless Adults in the U.S. J Gen Intern Med. 2018;33(9):1495-1497. doi:10.1007/s11606-018-4537-0

14. Young-Wolff KC, Klebaner D, Campbell CI, Weisner C, Satre DD, Adams AS. Association of the Affordable Care Act With Smoking and Tobacco Treatment Utilization Among Adults Newly Enrolled in Health Care. Med Care. 2017;55(5):535-541. doi:10.1097/MLR.0000000000000712

15. Maclean JC, Pesko MF, Hill SC. Public insurance expansions and smoking cessation medications. Econ Inq. 2019;57(4):1798-1820. doi:10.1111/ecin.12794

16. Koma JW, Donohue JM, Barry CL, Huskamp HA, Jarlenski M. Medicaid Coverage Expansions and Cigarette Smoking Cessation Among Lowincome Adults. Med Care. 2017;55(12):1023-1029. doi:10.1097/MLR.0000000000000821

17. Brantley EJ, Greene J, Bruen BK, Steinmetz EP, Ku LC. Policies Affecting Medicaid Beneficiaries' Smoking Cessation Behaviors. Nicotine Tob Res. 2019;21(2):197204. doi:10.1093/ntr/nty040

18. Donahoe JT, Norton EC, Elliott MR, Titus AR, Kalousová L, Fleischer NL. The Affordable Care Act Medicaid Expansion and Smoking Cessation Among Low-Income Smokers. Am J Prev Med. 2019;57(6):e203-e210. doi:10.1016/j.amepre.2019.07.004

19. Centers for Disease Control and Prevention. Survey Data \& Documentation. Updated Aug 31, 2020. Accessed May 18, 2021. https://www.cdc.gov/brfss/data_ documentation/index.htm

20. Garfield R, Orgera K, Damico A. The Coverage Gap: Uninsured Poor Adults in States that Do Not Expand Medicaid. Kaiser Family Foundation. January 2020. Accessed June 24, 2021. http://files.kff.org/attachment/ Issue-Brief-The-Coverage-Gap-Uninsured-Poor-Adultsin-States-that-Do-Not-Expand-Medicaid

21. Courtemanche Ch, Marton J, Ukert B, Yelowitz A, Zapata D. Early Impacts of the Affordable Care Act on Health Insurance Coverage in Medicaid Expansion and Non- 
Expansion States. J Policy Anal Manage. 2017;36(1):178210. doi:10.1002/pam.21961

22. Angrist JD, Pischke JS. Mostly Harmless Econometrics: An Empiricist's Companion. Princeton University Press; 2009. doi:10.2307/j.ctvcm4j72

23. Rocco P, Keller AC, Kelly AS. State Politics And The Uneven Fate Of Medicaid Expansion. Health Aff (Millwood). 2020;39(3):494-501. doi:10.1377/hlthaff.2019.01414

24. DiGiulio A, Jump Z, Yu A, et al. State Medicaid Coverage for Tobacco Cessation Treatments and Barriers to Accessing Treatments - United States, 2015-2017. MMWR Morb Mortal Wkly Rep. 2018;67(13):390-395. doi:10.15585/mmwr.mm6713a3

25. McMenamin SB, Halpin HA, Bellows NM. Knowledge of Medicaid coverage and effectiveness of smoking treatments. Am J Prev Med. 2006;31(5):369-374. doi:10.1016/j.amepre.2006.07.015

26. Tong VT, England LJ, Malarcher A, Mahoney J, Anderson B, Schulkin J. Clinicians' awareness of the Affordable Care Act mandate to provide comprehensive tobacco cessation treatment for pregnant women covered by Medicaid. Prev Med Rep. 2015;2:686-688. doi:10.1016/j.pmedr.2015.08.013

27. Arday DR, Tomar SL, Nelson DE, Merritt RK, Schooley MW, Mowery P. State Smoking Prevalence Estimiates: A Comparison of the Behavioral Risk Factor Surveillance Systemand Current Population Surveys. Am J Public Health. 1997;87(10):1665-1669. doi:10.2105/ajph.87.10.1665
CONFLICTS OF INTEREST

The authors have each completed and submitted an ICMJE form for disclosure of potential conflicts of interest. The authors declare that they have no competing interests, financial or otherwise, related to the current work. K. E. Hilts reports grants from the National Cancer Institute of the National Institutes of Health (Award Number T32CA117865), related to the current work. J. Blackburn reports grants from Robert Wood Johnson Foundation and from Indiana Family and Social Services.

\section{FUNDING}

No funding directly supported this study. Part of the time of KEH when preparing this manuscript was supported by the National Cancer Institute of the National Institutes of Health under Award Number T32 CA117865. The content is solely the responsibility of the authors and does not necessarily represent the official views of the National Institutes of Health.

\section{ETHICAL APPROVAL AND INFORMED CONSENT}

Ethical approval and informed consent were not required for this study as it used existing data from a national survey.

DATA AVAILABILITY

The data supporting this research is available from the following sources: https://www.cdc.gov/brfss/index.html

\section{AUTHORS' CONTRIBUTIONS}

KEH: conception and design, methodology, data acquisition, analysis, and interpretation, original draft writing, revisions, and preparation of final version. NM: conceptualization, methodology, interpretation of results, writing, reviewing, and editing of manuscript, and supervision. JB: conceptualization, methodology, analysis, interpretation of results, reviewing and editing of manuscript, and supervision. PJG, VAY and PKH: conceptualization, reviewing and editing of manuscript. All authors approved the final version to be published and agreed to be accountable for all aspects of the work.

PROVENANCE AND PEER REVIEW

Not commissioned; externally peer reviewed. 